\title{
Is There a Role for Surgery in BCLC B Hepatocellular Carcinoma?
}

\author{
Călin Popa ${ }^{1,2}$, Diana Schlanger ${ }^{1,2}$, Alina Buliarca' ${ }^{2}$, Tudor Mocan ${ }^{2,3}$, Bogdan Procopeț, $^{2,3}$ Zeno Spârchez ${ }^{2,3}$, \\ Nadim Al Hajjar ${ }^{1,2}$ \\ ${ }^{1}$ Surgery Department, Regional Institute of Gastroenterology and Hepatology "Prof. Dr. O. Fodor", Cluj-Napoca, Romania \\ 2“Iuliu Hațieganu" University of Medicine and Pharmacy, Cluj-Napoca, Romania \\ ${ }^{3}$ Gastroenterology Department, Regional Institute of Gastroenterology and Hepatology "Prof. Dr. O. Fodor", Cluj-Napoca, Romania
}

${ }^{*}$ Corresponding author: Diana Schlanger, MD Surgery Department

Regional Institute of Gastroenterology and Hepatology "Prof. Dr. 0. Fodor"

Cluj-Napoca, Romania

E-mail: schlanger.diana@yahoo.com

\section{Rezumat}

\section{Care este rolul chirurgiei în hepatocarcinomul BCLC B?}

Hepatocarcinomul intermediar, conform criteriilor Barcelona Clinic Liver Cancer (BCLC), cuprinde un număr larg de pacienți, cu caracteristici diverse, fiind definit de tumori multiple, funcție hepatică păstrată şi status de performanță bun. Tratamentul recomandat pentru acest stadiu este chemoembolizarea transarterială (TACE), dar există studii care discută rolul chirurgiei chiar şi în acest stadiu. Articolul de față raportează cazul unei paciente de 59 de ani, diagnosticată cu hepatocarcinom stadiu BCLC B (două tumori de 34, respectiv $25 \mathrm{~mm}$, în segmentele hepatice 5 şi 6 ), care au fost tratate cu succes prin rezecție chirurgicală. Această pacientă asociază factori de risc adiționali precum obezitate morbidă, hipertensiune portală clinic semnificativă şi trombocitopenie. În ciuda acestor factori, evoluția cazului a fost favorabilă. În concluzie, considerăm că tratamentul chirurgical are un rol important în managementul pacienților bine-selectati diagnosticați cu hepatocarcinom încadrat în stadiul BCLC B, iar o evaluare preoperatorie detaliată poate reduce riscul perioperator.

Cuvinte cheie: hepatocarcinom, criteriile BCLC, chirurgie hepatică

\section{Abstract}


Liver Cancer (BCLC) comprises a large number of patients, with diverse characteristics, being defined by multiple tumours, preserved liver function and good performance status. The recommended treatment for this stage is transarterial chemoembolization (TACE), but there are a few studies that discuss the role of surgery in this stage. We report a case of a 59-year-old woman diagnosed with BCLC B hepatocarcinoma (two tumours of 34 and $25 \mathrm{~mm}$, in liver segments 5 and 6) who was successfully treated with surgical resection. This patient had additional risk factors like morbid obesity, clinically significant portal hypertension, and thrombocytopenia. Despite these characteristics, the evolution was favourable. In conclusion, we believe that surgery has an important role in the treatment of well-selected BCLC B patients and a good preoperative assessment of the patient can minimize the perioperative risk.

Key words: hepatocellular carcinoma, BCLC criteria, liver surgery

\section{Introduction}

An adequate staging of hepatocellular carcinoma (HCC) is necessary in order to guide the management and treatment of these tumours, as well as for defining the prognosis in each particular case (1).

Despite having its limitations, the Barcelona Clinic Liver Cancer (BCLC) staging system is one of the most widely used and accepted classifications (1). It uses data regarding the number of tumours, tumour size, functional liver status and the patient's physical status to define five different stages (2).

According to the BCLC system, surgery is the treatment of choice in early stages (stage 0 and stage A), while other treatment options (transarterial chemoembolization $=$ TACE or sorafenib) are recommended in intermediate and advanced stages (3). Lately, there have been discussions regarding expanding the indications for surgical resection to patients included in BCLC B stage (intermediate stage) $(4,5)$; there has been proof that surgical resection may achieve a better overall survival $(3,4)$.

Intermediate stage hepatocarcinoma is defined by multinodular disease, preserved liver function and good performance status. Therefore, patients included in BCLC B stage are part of a heterogenous population (5), with diverse characteristics, that might benefit from a more personalized approach in their treatment.

Indications for surgical resection in nonearly HCC remain controversial. We present the management of an intermediate stage HCC, with multiple associated risk factors that supports the hypothesis that surgical resection can be a treatment option in wellselected patients.

\section{Case Report}

We present the case of a 59-year-old female patient with a 10-year history of viral $\mathrm{C}$ hepatitis; she followed an interferon-free treatment with a sustained virological response. In March 2019, she was diagnosed with liver cirrhosis: Fibroscan indicated F4 Metavir stage. The patient had a BMI of 46.8 $\mathrm{kg} / \mathrm{m}^{2}$ and no other associated conditions.

In July 2019, she had a follow-up appointment with the gastroenterologist. Routine imagistic evaluation by abdominal ultrasound revealed a suspicious nodule in the liver. Contrast-enhanced ultrasound described a hypoechoic subcapsular lesion of about $2 \mathrm{~cm}$, between segment 5 and 6 of the liver; after the administration of the contrast agent, the lesion showed intense enhancement in the arterial phase with inhomogeneous wash-out in the portal phase. Another nodule of less than $1 \mathrm{~cm}$, with the same characteristics was identified just under the hepatic capsule, in 

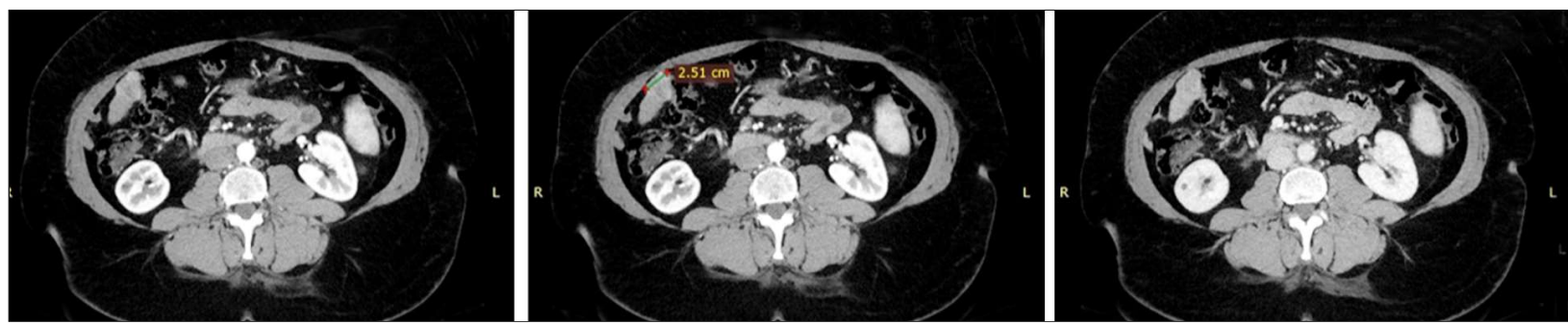

Figure 1. CT scan: axial view (July 2019). The first tumour - hepatic segment $5 / 6$ (from left to right: arterial phase - tumour dimensions - venous phase)
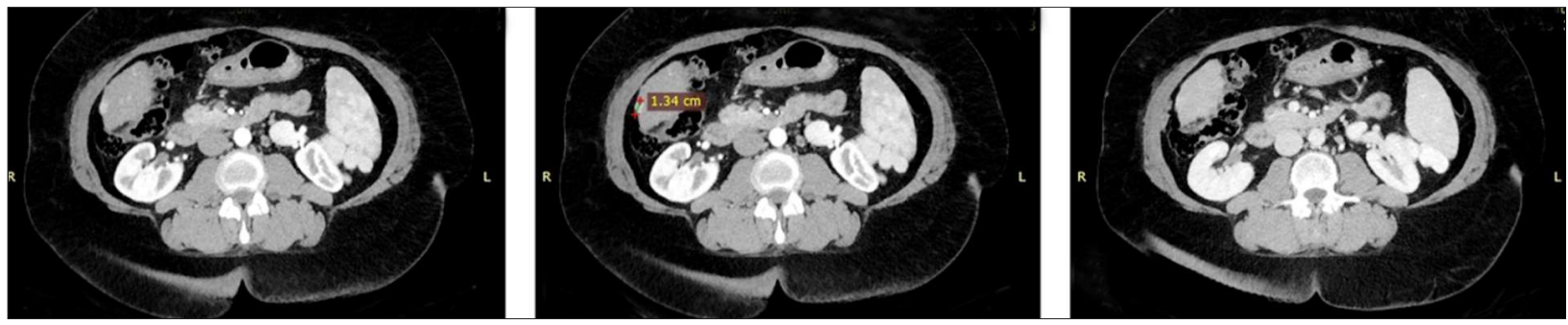

Figure 2. CT scan: axial view (July 2019). The second tumour - hepatic segment 6 (from left to right: arterial phase -tumour dimensions - venous phase)

hepatic segment 6. A CT scan was performed, and the two lesions were described. A $25 \mathrm{~mm}$ tumour was identified at the limit between liver segments 5 and 6 , with a subcapsular situation, with inhomogeneous arterial enhancement and inhomogeneous wash-out; the imagistic suspicion was of hepatocellular carcinoma (Fig. 1). Another subcapsular tumour of $13 \mathrm{~mm}$ was described in liver segment 6; it had arterial enhancement but no wash-out, being considered a dysplastic lesion (Fig. 2). Blood tests showed moderate thrombocytopenia, normal bilirubin and albumin levels. At this time, the patient was staged as BCLC A (two nodules up to three centimeters, good performance status, preserved liver function). The patient did not undergo any treatment and there was no follow-up for about one year, the patient avoiding to make an appointment in the current pandemic context.

In September 2020, the patient presents to the gastroenterology department for reevaluation. After more than one year from the initial diagnosis, a CT scan was effectuated: the first tumour, described at the border between segments 5 and 6 has now approximately $34 \mathrm{~mm}$ (Figs. 3, 4), while the second tumour, localized in segment 6 has 24 $\mathrm{mm}$ and imagistic characteristics of a hepa-
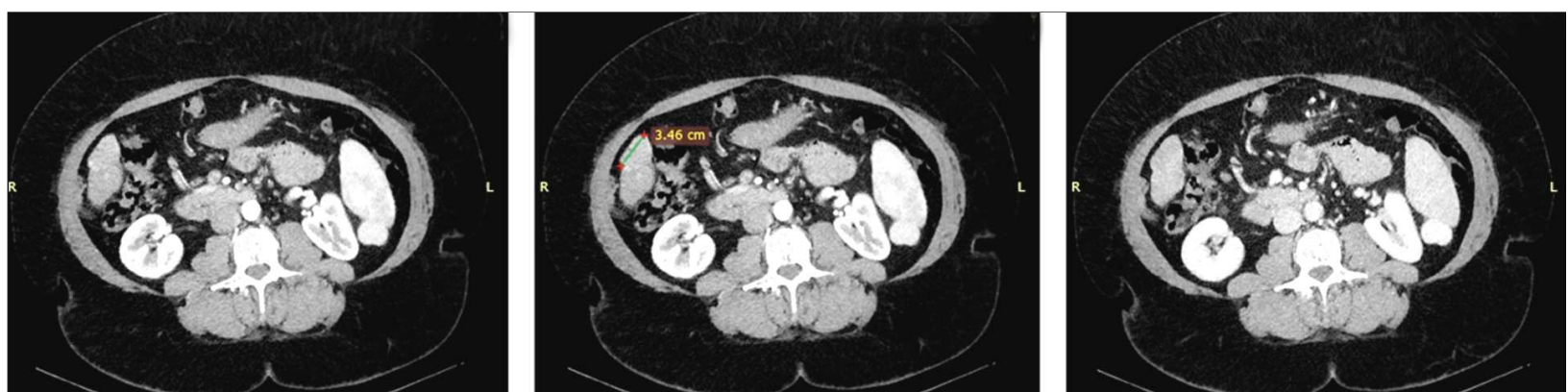

Figure 3. CT scan: axial view (September 2020). The first tumour - hepatic segment $5 / 6$ (from left to right: arterial phase - measured tumour - venous phase) 


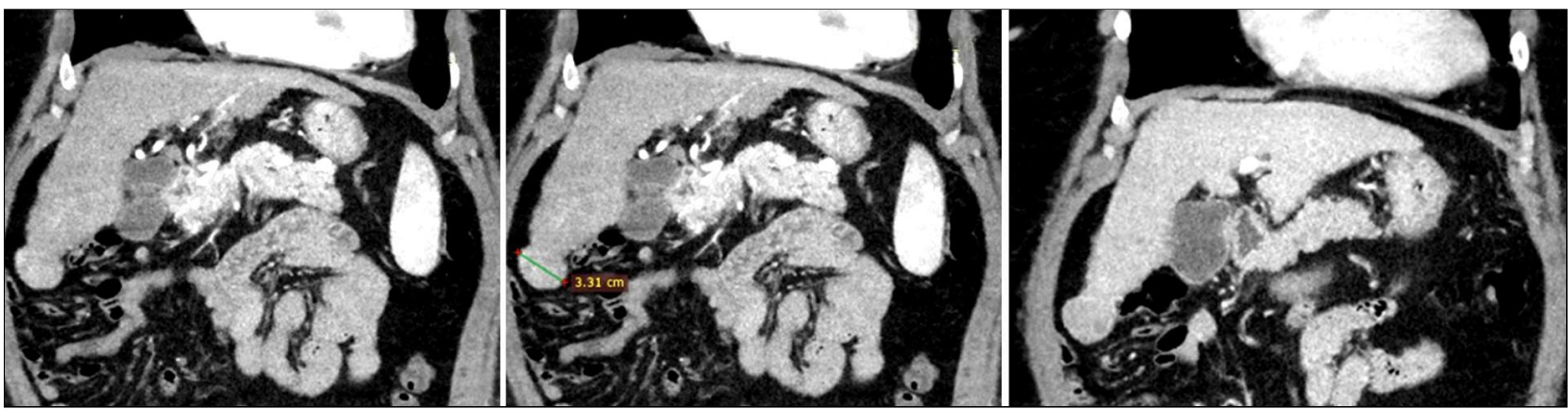

Figure 4. CT scan: coronal view (September 2020). The first tumour - hepatic segment 5/6 (from left to right: arterial phase - measured tumour - venous phase)

tocarcinoma as well (heterogenous arterial hyperenhancement and heterogenous washout) (Figs. 5, 6). The tumours were evaluated by contrast-enhanced ultrasound, which confirmed their position and typical characteristics for a hepatocellular carcinoma. Blood tests showed thrombocytopenia (63000/ uL), mildly elevated bilirubin level $(1.4 \mathrm{mg} / \mathrm{dl})$, the albumin level was in normal ranges $(3.7 \mathrm{~g} / \mathrm{dl})$, the INR was 1.27 , and no other significant pathological alterations were identified. Given all these data, we could calculate a Child-Pugh score of 5 points, the diagnosis being Child A liver cirrhosis. The evolution of the tumours during the past year, one of them being larger than $3 \mathrm{~cm}$ included the patient in BCLC stage B. BMI was 52.5 $\mathrm{kg} / \mathrm{m}^{2}$, the patient being morbidly obese.

Considering the characteristics of the two tumours, a multidisciplinary team considered
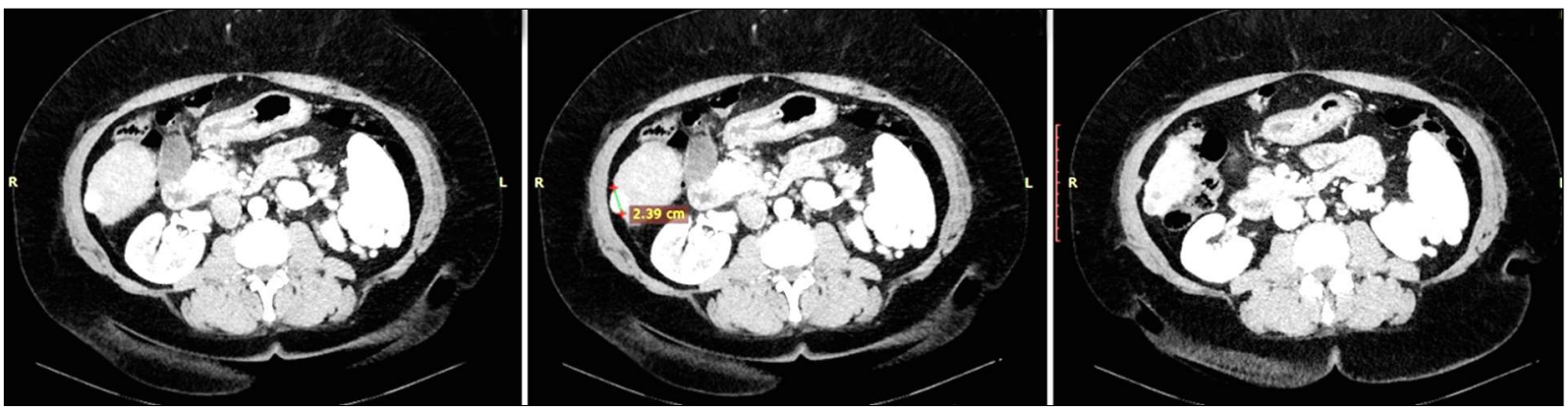

Figure 5. CT scan: axial view (September 2020). The second tumour - hepatic segment 6 (from left to right: arterial phase - measured tumour - venous phase)
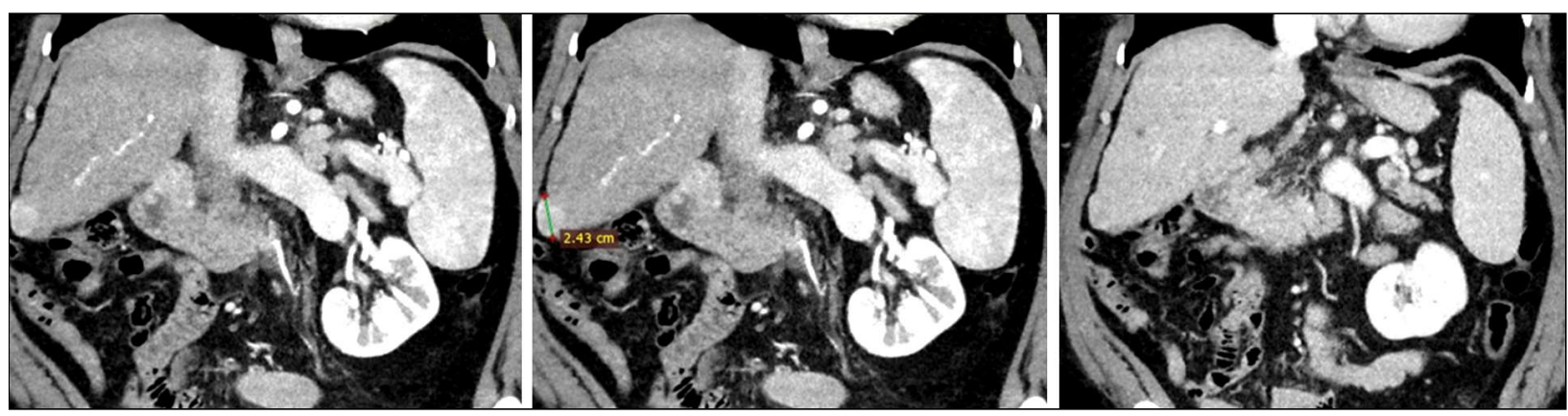

Figure 6. CT scan: coronal view (September 2020). The second tumour - hepatic segment 6 (from left to right: arterial phase - measured tumour - venous phase) 


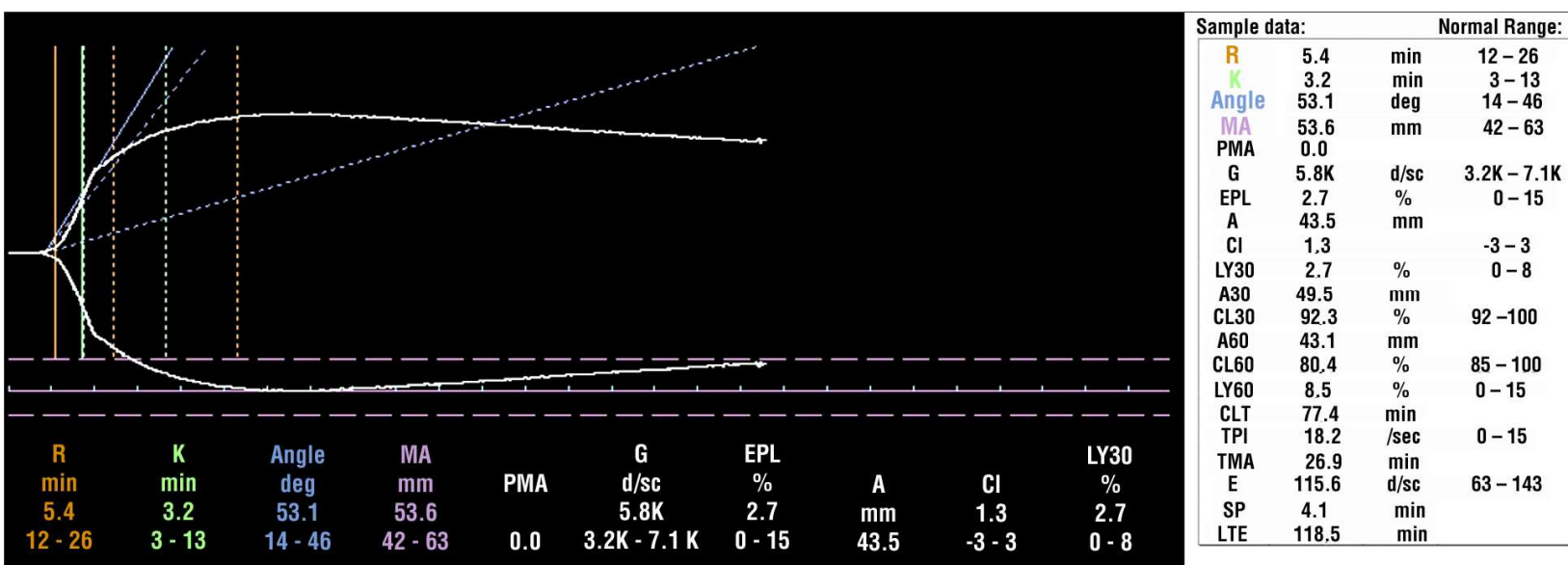

Figure 7. Thromboelastography $(\mathrm{R}$ - reaction time, $\mathrm{K}$ - kinetics, MA - maximum amplitude, $\mathrm{Cl}$ - clot index, LY 30 - $\%$ of fibrinolysis at 30 minutes after MA, LY60 - \% of fibrinolysis at 60 minutes after MA)

that this patient might benefit from surgery. A cardiac and respiratory evaluation was indicated; a normal cardiac function and a mild ventilatory obstruction on spirometry permitted a safe surgical intervention. The hepatic venous pressure gradient was also measured, a value of $12 \mathrm{mmHG}$ indicating clinically significant venous hypertension. We also performed a thromboelastography (TEG) in order to test the efficiency of hemostasis considering that thrombocytopenia was present. A TEG 5000 Hemostasis Analyzer was used. The result showed a hypercoagulation state with secondary fibrinolysis. Despite thrombocytopenia, the test showed a normal MA (maximum amplitude).

After the preoperative evaluation, we decided to proceed with the surgical intervention. A marginal resection of liver segments 5 and 6 was performed (Fig. 8). The postoperative evolution was favourable, the patient being discharged on postoperative day 5 . The final histopathological report described two tumours of 35 and $24 \mathrm{~mm}$, with hepatocellular carcinoma histology, and clear resection margins.

\section{Discussion}

The presented case illustrates the use of surgical resection as the treatment of choice for a patient beyond BCLC criteria for surgery. Although the patient had no indication for surgery based on BCLC criteria and had additional risk factors (thrombocytopenia, clinically significant HVPG, obesity), a multidisciplinary team decided that surgical intervention could be the best option for this

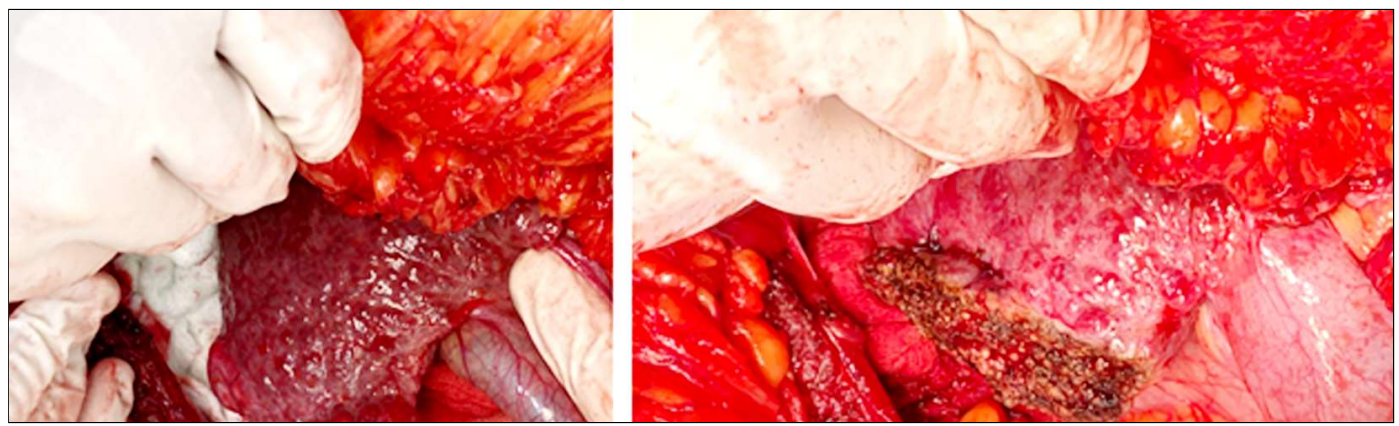

Figure 8. Intraoperative images. Left - The two tumours. Right - The resection margin 
patient, given the subcapsular localization of the two tumours and the possibility of including them in the same marginal resection. We intend to integrate the particularities of our case in the context of the published literature, in order to discuss the controversial subject of surgical resection in non-early HCC.

Hepatocellular carcinoma (HCC) is a heterogenous disease, from its etiology to its clinical-biological behaviour (6). Different staging systems have been proposed in order to standardize the management of this disease and offer the best prognosis for each patient; the Barcelona Clinical Liver Cancer (BCLC) classification is used in most centers. Even with the current classifications, the best treatment for each stage is still poorly understood and controversies exist especially regarding non-early stages, for which noncurative treatment options are recommended. Intermediate stage disease (BCLC B) comprises a very heterogenous group of patients on its own, therefore posing unique challenges for its therapeutic management (5). Due to this reason, there have been attempts to develop and validate subclassifications $(7,8)$ for a better stratification of the patients included in this stage.

Several studies have discussed the role of surgery in intermediate-stage patients, with promising results. Ciria et al. (9) concluded that surgical resection can offer survival benefit with acceptable safety in BCLC B patient; the major advantage of resection is the fact that it offers a curative option of treatment for these patients. Other studies $(3,10,11)$ report good results, while recommending the careful selection of patients for surgery. Wada et al. (11) proposed the following indications for surgical intervention in BCLC B patients: platelet count $>80000$ $/ \mathrm{mm}^{3}$, total bilirubin in normal range, appropriate residual liver volume and no ascites. Judging by these criteria, our patient had a mildly elevated bilirubin level and thrombocytopenia: we consider that even with these issues, if a thorough preoperative evaluation is performed, surgery can be a viable option.

From its introduction in 1985, TEG (a viscoelastic test for the global evaluation of hemostasis) has been used in liver transplantation centers for the evaluation of hemostasis in patients undergoing liver transplantation and for the management of blood transfusions $(12,13)$. Despite the old belief that cirrhotic patients are naturally anticoagulated, the studies from the last decades have shown that they express a normal balance of hemostasis (14-17). Despite thrombocytopenia and decreased levels of coagulation factors (proand anti-coagulant), these patients are more prone to hypercoagulability than bleeding due to a normal or even increased level of thrombin generation. (18,19). Our patient, despite having a low platelet count, expressed a hypercoagulative state associated with secondary fibrinolysis as shown by TEG. Contrary to what conventional management would recommend - platelet transfusion, she had to be anticoagulated. More factors obesity, cirrhosis, and hepatocarcinoma - could have contributed to her hypercoagulative state. With the use of TEG, we avoided an unnecessary platelet transfusion, and the patient could be operated in safe condition.

The recommended treatment by BCLC criteria for intermediate stage patients is TACE, according to clinical practice guidelines. In the medical literature, a few studies compared TACE and surgical resection (20). A meta-analysis (21) demonstrated that surgical intervention has a statistically significant survival benefit compared with TACE in BCLC B patients. Another study (22) compared the quality of life (QoL) between two groups of patients who underwent surgery or TACE: long-term QoL was better in the resection group. The same study reported that surgical treatment temporarily decreased QoL on the short term: in our presented case, the patient recovered quickly after the intervention (even with morbid obesity being an important risk factor), being discharged on postoperative day 5 .

Although, the advantages of surgical treatment in BCLC B patients are significant, the risk of recurrence exists and a close follow-up is important. A recent study shows that early 
recurrence rate is higher for patients beyond BCLC criteria, but after 2 years it is similar between BCLC 0/A and BCLC B/C after the second postoperative year (23). It is important to keep in mind this fact in order to enssure a close surveillance of the patient in early postoperative period.

Different treatment methods are used today as a bridging therapy to liver transplantation. Surgical resection may be a good choice of bridging therapy since it provides a better control of tumor growth, as well as an evaluation of tumor biology by pathological analysis (24).

While promising results regarding the role of surgery in intermediate stage HCC exist, a comprehensive stratification of the patient who would benefit the most from this course of treatment is very difficult to accomplish, especially due to the heterogeneity of the BCLC B stage. For this reason, we consider that an attentive evaluation of each case, and a discussion within a multidisciplinary team is the best way of making the best treatment choice for each patient. In our particular case, risk factors (liver cirrhosis, morbid obesity, thrombocytopenia, increased HVPG) had to be put in balance with the favourable factors that permitted the resection (the tumours localized in the anterior segments of the liver, superficial situation of tumours, the proximity of the two tumours, the cardiorespiratory assessment results, and the TEG results).

We believe that every classification has its limits, which can be overcome by clinical judgement in complex cases. The general status of the patient as well as the technical difficulty of the resection should be taken into consideration, thus we can evaluate the possibility of offering a treatment with curative intent to as many patients as possible.

\section{Conclusions}

Surgical resection is not recommended as a treatment for intermediate stage hepatocellular carcinoma by the BCLC staging system. However, our presented case supports the fact that well-selected patients, with a proper preoperative evaluation, can benefit from surgery. The current tendency is to perform surgical resection whenever possible, even beyond general recommendation, this type of approach being supported by our presented case as well.

\section{Conflict of Interest}

The authors declare no conflicts of interests.

\section{References}

1. Tellapuri S, Sutphin PD, Beg MS, Singal AG, Kalva SP. Staging systems of hepatocellular carcinoma: A review. Indian J. Gastroenterol. 2018; 37(6):481-491.

2. Pons F, Varela M, Llovet JM. Staging systems in hepatocellular carcinoma. HPB (Oxford). 2005;7(1):35-41

3. Guo H, Wu T, Lu Q. Surgical resection improves long-term survival of patients with hepatocellular carcinoma across different Barcelona Clinic Liver Cancer stages. Cancer Manag Res. 2018;10:361-369.

4. Chang WT, Kao WY, Chau GY, Su CW, Lei HJ, Wu JC, et al. Hepatic resection can provide long-term survival of patients with non-early-stage hepatocellular carcinoma: extending the indication for resection? Surgery. 2012;152(5):809-20.

5. Bolondi L, Burroughs A, Dufour JF, Galle PR, Mazzaferro V, Piscaglia F, et al. Heterogeneity of patients with intermediate (BCLC B) Hepatocellular Carcinoma: proposal for a subclassification to facilitate treatment decisions. Semin. Liver Dis. 2012;32(4):348-59.

6. Zhong JH, Peng NF, You XM, Ma L, Xiang X, Wang YY, et al. Tumor stage and primary treatment of hepatocellular carcinoma at a large tertiary hospital in China: A real-world study. Oncotarget. 2017;8(11): 18296-18302.

7. Zhang YF, Zhou J, Wei W, Zou RH, Chen MS, Lau WY, et al. Intermediatestage hepatocellular carcinoma treated with hepatic resection: the NSP score as an aid to decision-making. Br. J. Cancer. 2016;115(9):1039-1047.

8. Hiraoka A, Kumada T, Nouso K, Tsuji K, Itobayashi E, Hirooka M, et al. Proposed New Sub-Grouping for Intermediate-Stage Hepatocellular Carcinoma Using Albumin-Bilirubin Grade. Oncology. 2016;91(3):153-61.

9. Ciria R, Lopez-Cillero P, Gallardo AB, Cabrera J, Pleguezuelo M, Ayllon MD, et al. Optimizing the management of patients with BCLC stage-B hepatocellular carcinoma: Modern surgical resection as a feasible alternative to transarterial chemoemolization. Eur. J. Surg. Oncol. 2015;41(9):1153-61.

10. Bell R, Pandanaboyana S, Lodge JPA, Prasad KR, Jones R, Hidalgo E. Primary liver resection for patients with cirrhosis and hepatocellular carcinoma: the role of surgery in BCLC early $(A)$ and intermediate stages (B). Langenbecks Arch. Surg. 2017;402(4):575-583.

11. Wada H, Eguchi H, Noda T, Ogawa H, Yamada D, Tomimaru $Y$, et al. Selection criteria for hepatic resection in intermediate-stage (BCLC stage B) multiple hepatocellular carcinoma. Surgery. 2016;160(5):1227-1235.

12. Wang SC, Shieh JF, Chang KY, Chu YC, Liu CS, Loong CC, et al. Thromboelastography-guided transfusion decreases intraoperative blood transfusion during orthotopic liver transplantation: Randomized clinical trial. Transplant. Proc. 2010;42: 2590-2593.

13. Kang YG, Martin DJ, Marquez J, Lewis JH, Bontempo FA, Shaw BW Jr, et al. Intraoperative changes in blood coagulation and thrombelastographic monitoring in liver transplantation. Anesth. Analg. 1985;64:888-896.

14. Tripodi A. Hemostasis abnormalities in cirrhosis. Curr. Opin. Hematol. 2015;22(5):406-12.

15. Tripodi A, Primignani M, Mannucci PM, Caldwell SH. Changing Concepts of Cirrhotic Coagulopathy. Am. J. Gastroenterol. 2017;112(2):274-281.

16. Tripodi A, Mannucci PM. The coagulopathy of chronic liver disease. N. Engl. 
J. Med. 2011;365(2):147-56.

17. Kujovich JL. Coagulopathy in liver disease: a balancing act. Hematology Am Soc Hematol Educ Program. 2015;2015:243-9.

18. Tripodi A, Salerno F, Chantarrangkul V, Clerici M, Cazzaniga M Primignani $\mathrm{M}$, et al. Evidence of normal thrombin generation in cirrhosis despite abnormal conventional coagulation tests. Hepatology. 2005 41(3):553-558

19. Gatt A, Riddell A, Calvaruso V, Tuddenham EG, Makris M, Burroughs AK. Enhanced thrombin generation in patients with cirrhosis-induced coagulopathy. J. Thromb. Haemost. 2010;8(9):1994-2000.

20. Labgaa I, Taffe P, Martin D, Clerc D, Schwartz M, Kokudo N, et al. Comparison of Partial Hepatectomy and Transarterial Chemoembolization in Intermediate-Stage Hepatocellular Carcinoma: A Systematic Review and Meta-Analysis. Liver Cancer. 2020;9(2):138-147.

21. Yang B, Zheng B, Yang M, Zeng Z, Yang F, Pu J, et al. Liver resection versus transarterial chemoembolization for the initial treatment of Barcelona Clinic Liver Cancer stage B hepatocellular carcinoma. Hepatol. Int. 2018; 12(5):417-428

22. Xie ZR, Luo YL, Xiao FM, Liu $Q, M a Y$. Health-related quality of life of patients with intermediate hepatocellular carcinoma after liver resection or transcatheter arterial chemoembolization. Asian Pac. J. Cancer Prev. 2015; 16(10):4451-6.

23. Tsilimigras DI, Bagante F, Moris D, Hyer JM, Sahara K, Paredes AZ, et al. Recurrence Patterns and Outcomes after Resection of Hepatocellular Carcinoma within and beyond the Barcelona Clinic Liver Cancer Criteria. Ann. Surg Oncol. 2020;27(7):2321-2331.

24. Coletta M, Nicolini D, Benedetti Cacciaguerra A, Mazzocato S, Rossi R, Vivarelli M. Bridging patients with hepatocellular cancer waiting for liver transplant: all the patients are the same? Transl. Gastroenterol. Hepatol. 2017;2:78

\section{Reviewer Comments}

The article is well structured, featuring an well investigated clinical case. The role of surgery in stage BCLB $\mathrm{B}$ is an interesting topic introduced in debate more than a decade ago (1), and more and more clinical evidence sustain its effectiveness $(2,3)$. However, it cannot be analyzed / supported through the prism of a singular case, but on large study groups. Also, we have to admit that in this case the first-line surgical treatment (small subcapsular nodules on the edge lower part of the liver) is the laparoscopic approach. Nevertheless, even though just a clinical case, this is part of the concept of pushing the boundaries of the BCLC classification and it is welcomed as such.

1. Torzilli G, Donadon M, Marconi M, Palmisano A, Del Fabbro D, Spinelli A, Botea F, Montorsi M. Hepatectomy for stage B and stage C hepatocellular carcinoma in the Barcelona Clinic Liver Cancer classification: results of a prospective analysis. Arch Surg. 2008;143(11):1082-90. .

2. Kamiyama T, Orimo T, Wakayama K, Shimada S, Nagatsu A, Yokoo H, Kamachi H, Yamashita K, Shimamura T, Taketomi A. Survival outcomes of hepatectomy for stage B Hepatocellular carcinoma in the BCLC classification. World J Surg Oncol. 2017;15(1):156.

3. Tsilimigras DI, Bagante F, Sahara K, Moris D. Hyer JM, Wu L, Ratti F, Marques HP, Soubrane O, Paredes AZ, Lam V, Poultsides GA, Popescu I, Alexandrescu S, Martel G, Workneh A, Guglielmi A, Hugh T, Aldrighetti L, Endo I, Pawlik TM. Prognosis After Resection of Barcelona Clinic Liver Cancer (BCLC) Stage 0, A, and B Hepatocellular Carcinoma: A Comprehensive Assessment of the Current BCLC Classification. Ann Surg Oncol. 2019;26(11):3693-3700. 